\title{
Research on the Legal Protection of the Network Virtual Property
}

\author{
Ren Xuejng \\ College of Humanities and Law,of Hebei United University, \\ Hebei United University ,HUU \\ Tangshan Hebei China ,13731533598 \\ renxjing@163.com
}

\begin{abstract}
Along with the rapid development of the network games in China, the disputes around the virtual property occur frequently, but our country's existing law doesn't have clear rules to solve the problems. To speed up the related legal system construction in order to protect the healthy development of the network has become an important subject in the network game industry .This paper discusses the nature and characteristics of virtual property, the infringement responsibility of the network virtual property and the legal protection for advice.
\end{abstract}

Keywords- network virtual property; civil law protection; suggestions

\section{INTRODUCTION}

According to China Internet network information center in July 2009 issued by the 24th times China Internet network development statistics report, China's Internet users scale has reached 338 million person, among them netizens network game service utilization rate is $64.2 \%$, the user scale up to 217 million people. According to China Internet network information center statistics show that $61 \%$ of the game players had "virtual property" stolen experience. Tencent company statistics, the company every day peak about 100000 people reflect QQ password stolen, not including those who actually stolen without representation of netizens. These network theft behavior of existence, not only the serious influence and damage the normal order of the network, and seriously damage the game companies and Internet users' interests, and crack down on network burglary is urgent.

\section{THE OVERVIEW OF THE NETWORK VIRTUAL PROPERTY}

\section{A. The Concept of the Network Virtual Property}

The network virtual property" have broad and narrow points. In the general sense of the understanding, as long as it is digital, intangible property form can into the category of virtual property, is all exist in particular network virtual space has specificity of virtual objects, including ID, QQ number, E-mail, virtual currency, game equipment, etc., and its extension is very extensive. With the development of network technology, this kind of virtual property may also increase, such as the network bank ID. From the point of view of narrow understanding is originally depends on the network of the space virtual environment and existing game resources, including account Numbers game, game role, and in the process of accumulating "currency", "real estate", "equipment" (weapons, armor, pharmacy, etc.), "pet" and so on the goods. This paper from the special Angle definition of network virtual property.

\section{B. The Nature of the Network Virtual Property}

The network virtual property belongs to the intangible property, it is neither like tangible property as physical presence, also don't like intellectual achievements that can have materialized form of expression, it is a kind of virtual intangible property. Say it is intangible, on the one hand, embodied in it produces and surviving in the network of them; On the other hand, embodied in its virtual sex. In the concept of the use of "virtual" not refers to the value of this property is unreal, more not refers to the legal nature of such property is illusory, but to with the traditional property form provide appropriate distinguish, show that the virtual property for network virtual space and exist. With respect to its essence character, the network virtual property is stored in a computer network server in various specific data and information, subject to these specific data and information enjoys the rights, which reflect a kind of information rights. These specific data and information is invisible, so, the network virtual property is also invisible. Network players through the purchase, exchange and tangible way, its all tangible property into intangible property, and in the network virtual space to meet their own interests.

\section{C. the Characteristics of the Network Virtual Property}

With the development of network and network virtual property disputes increasing, the network virtual property is no longer completely "virtual", infringing upon the virtual property has breakthrough virtual space and reality to the space transfers, has the certain reality. The virtual property not only virtual or independent existence in the virtual society, but gradually the real property and social reality established corresponding or conversion relation. Therefore, the virtual property has the realistic society the true and the value of the property. It has the following features:

The network virtual property is virtual.This means that the virtual property of network games virtual environment has a natural dependence, cannot be separated from the network game and exist. Virtual property of network games rely on performance in various roles, equipment and game currency and concrete is stored in the game server of electronic data, it is only through the specific network game to expression comes out, can't put the network virtual property in the game 
to another network game went up use. The game server data disappeared, the virtual property also disappeared.

The network virtual property has technology restriction, it is to point to network play the role of attribute scope, equipment properties range are network games predetermined, although in this range have certain volatility, but always also super out the range. What level of monster off what level of equipment, drop the probability of equipment, each equipment upgrade range and higher explosion probability is the game program prior setting good. High level monsters just drop high-grade equipment, equipment upgrade, the more and more easy to rise detonation (gone). It is this technology restrictive makes the best material with scarcity.

The network game also inevitably has the characteristic, although the game also exist in the trading system, but the virtual society after all is connected and social reality, when so-called "gourmet" can't use in-game value measured or equivalent exchange, or players do not have in the game within the equivalent exchange capacity, will naturally think of realistic society to make up for, the network virtual property and the form of goods traded in the realistic society, now more and more network virtual property transaction to the emergence of the web site, and make the network virtual property transaction presents the characteristics of electronic commerce.

Players in the game process input financial, energy and intelligence, through the LianJi and do the task to improve the level of virtual characters, and get the corresponding equipment and game currency. Players into the money and energy difference, directly reflected in the game players have the role of grade and gourmet equipment of different levels and the quantity. As a result of the virtual property distribution imbalance and players to redistribute the virtual property demand led to the transfer of the virtual property, and then derive the so-called "professional players," these players spontaneous to individual or organization way involved in the game, the game role exercise to high grade, or for those scarce advanced equipment after the high-level characters, equipment and other network virtual property in reality to sell, in order to get profit, and become a professional.

\section{THE LEGAL PROtection SituAtion OF THE NETWORK VRTUAL PROPERTY}

\section{A. the Present Legal Rrotection of China's Network Virtual Property}

In our country, the network virtual property and didn't get effective protection, investigate its reason lies in the existing laws, including the constitution and the civil law only for citizens' legal income, savings, housing and other lawful property be recognized, and not the legitimacy of the virtual property defined. In the consumer rights and interests protection law ", Internet users to the virtual property rights will not belong to the existing consumer rights in any one, so there are many players in lost after property TouSuWuMen phenomenon. Theoretically, protect the network virtual property has the necessity. The network game industry rapid development at the same time, the network game triggered some legal problems and social problems also arise, the network virtual goods and game equipment legal status, operators legal liability, the player's rights and interests protection and so on many legal problems and social problems directly affect the China's online game industry's healthy development. Moreover, the network virtual property is subject spent a lot of time, money and energy obtained, the subject is of positive significance, it is in the interests of the main body, the law should admit the property interests, and protect the interests of property. Therefore, to protect the lawful rights and interests of the network game, and promote the healthy development of the network business, to speed up the related legal system construction in order to protect the healthy development of the network game industry, network game industry development has become an important subject, network "hollow bridge" are in urgent need of legal plugging "leak". This paper, from the Angle of the civil law on the protection of virtual property.

\section{B. Tort Liability of the Network Vrtual Property}

The civil law of tort liability imputation principle has three: the principle of fault liability and no-fault liability principle and fair liability principle. Using different the principle of liability fixation, the form element and the responsibility of the burden of proof for the compensation for damages, the method is also different. The tort liability imputation principle to the principle of fault liability is given priority to, for special tort the presumption of fault liability principle and the principle of liability without fault. The network virtual property in essence is a kind of information rights, it produces and surviving in the network in, this information was actually network company control. This particular data and information in fact exist in Internet bar computer server inside, Internet cafe can monitor the information. Therefore, the network company and Internet cafe common control these information, and Internet users or game players can't actual control these information. This kind of "information partial in" or "information asymmetry" situation make Internet users or game players in the network companies, Internet bar in front of absolute vulnerable position. The civil law from the fair principle, should emphasize the protection of the legitimate interests of the weak. Therefore, the network virtual property infringement responsibility imputation principle shall adopt the presumption of fault, implement "onus probandi inversion", by the person prove that he has no fault.

\section{The Network Virtual Property Tort Liability of the Constitutive Requirements}

Enroach on network virtual property behavior. The network virtual property, as a special kind of property, nature is a kind of information rights. Because information could be controlled artificially namely transfer, copy and modify, therefore, the infringement of the property behavior generally includes steal, leakage control virtual property password behavior without delete virtual, illegal to sell the virtual property, etc.

The network virtual property infringement facts. Due to the behavior of the infringer, the right holder to lose control of the virtual property is not normal to dominate the property. For example, the right holder of the virtual property stolen password, the right holder virtual property to reduce or be 
replaced facts and so on.

Violation behavior and damage to the causal relationship between the facts. The network virtual property loss is caused by the infringement by the infringer. This kind of causal relation can be directly, also can be indirectly (because information vulnerable to transfer, diffusion and modify)

Because of the network virtual property tort liability the presumption of fault liability, so the actor's subjective fault presumption is the law, the victim does not need to produce evidence to prove. If a person or assume responsibility, need provides evidence proving that he does not have fault, or laws are constructive actor existence fault.

\section{The Network Virtual Property Tort Liability of the Way}

Our country "tort liability law the provisions of article 15:" assume tort responsibility way are mainly: (1) to stop the infringement, eliminate the obstruction (2); (3) to eliminate risk; (4) restitution of property; (5) restoration; (6) for compensation; (7) offer an apology; and (8) eliminate the influence, rehabilitated. Above assume tort responsibility way, can be applied exclusively or concurrently." Because of the network virtual property in essence is a kind of information rights, and information can be artificial control. Information can pass, copy and modify, and restore its original state. Therefore, the network virtual property of tort liability is the main means to stop the infringement, restitution of property, restore to the original and compensate for the losses. That is when a virtual property infringement, the subjects of the right person may be required to stop the infringement, may require the other party returned to control the virtual property the password or resume own inventory of virtual property. For the compensation of losses, can be real money, also can compensate the same virtual property.

\section{Legal Protection Suggestions of THE Network VIRTUAL PROPERTY}

\section{A. Judicial Interpretation Way}

China's "general principles of the civil law" article 75 paragraph 1 "citizens personal property, including citizens' legal income, housing, savings, articles for daily use, cultural relics, books data, trees, cattle and the law allows citizens all the production material and other lawful property." In the middle of the "other lawful property" more interpretations, network virtual property included in the "other lawful property" inside. Or to the "consumer rights and interests protection law" article 2: "consumers for life consumption need to purchase or use of a commodity or receiving a service, its rights protected by this law, the stipulations, the other relevant laws and regulations to protect. For expanding explanation, the purchase network service behavior also regard as consumption behavior, and so on the net gain of virtual property can be applicable to the provisions of article 7 "consumers in the purchase or use of a commodity or receipt of a service, enjoy the safety of person and property damage right. A consumer shall have the right to require the operator to provide goods and services, and meet with requirements for the safety of person and property." The security of network property safety.

\section{B. The Legislation Way Alone}

Network economy has become a industry, it is necessary to specifically formulated a "network" or the "information law, and the network related to all kinds of" net matter relationship "standard. In the law, the specific provisions of the network virtual property definition, nature and scope, the network virtual property relations subject, object, content and network virtual property acquisition modes and the mode and liability way, specific provision Internet users, Internet bar, the network company rights and duties in the relationship between each other. This approach is difficult, but can fundamentally solve the problem. .

\section{Administrative management way}

This can be regarded as a kind of emergency measures. By information industry department jointly with the relevant departments, formulate network management regulations as soon as possible, to strengthen the management of network companies, Internet cafes, clear legal network virtual property shall be protected by law, infringes on the legal network virtual property behavior of punishment. Set up the network virtual property transaction neutral third party, to the fictitious property storage, evaluation and trading, a netizen identity registration on the network virtual property can also take registration system.

\section{REFERENCES}

[1] QinZuWei. Theory for the protection of virtual property [J].journal of academic exploration,, pp. 74, May 2005.

[2] WangHui. The network virtual property and the nature of the civil law protection [J].journal of rule of law and economy,March 2006.

[3] ChenXuQin. Theory of the legal nature of virtual property in network [J]. Journal of zhejiang province, May 2004

[4] YangLiXin: theory network virtual property right attribute and its basic rules [N]. National prosecutors college journal, June 2004.

[5] LiuDeLiang. Theory of virtual objects property. Inner Mongolia social science (han Chinese version),June.2004

[6] ZengHaiRe. Theory "virtual property" legalization. Contemporary method. May 2005

[7] GaoMei. Try to talk about the protection of virtual property. [J]Shandong youth management cadre institute journal, February 2008

[8] LiuJia.The network virtual property of the nature and legal protection [J]. J legal system and social. December 2007.

[9] ZhaoXueJun. Shallow discussion network virtual property "legal protection [J]. Journal of sichuan education college. March 2009 